\title{
Use of propofol and thiopentone sodium as anaesthetic agent in electroconvulsive therapy for psychiatric disorders: A comparative study
}

\author{
Kiran B Sonawane ${ }^{1^{*}}$, Anil Patil $^{2}$ \\ ${ }^{1}$ Assistant Professor, ${ }^{2}$ Associate Professor, Department of Anesthesia, Government Medical College \& Hospital, Jalgaon, Maharashtra, \\ INDIA. \\ Email: drkiran6669@gmail.com
}

\begin{abstract}
Background: Electroconvulsive therapy was introduced about a half century ago as treatment for schizophrenia and depression, and was used exclusively for this disorder for many years. Material and methods: 60 patients were selected and divided in 2 groups and given thiopental sodium in group 1 and propofol in group 2. Time for induction of seizure with hemodynamic parameters and side effects were studied. Results: Systolic blood pressure was not significantly different in both group whereas diastolic blood pressure was less with propofol as compared to that of thiopentone, pulse rate after induction was seen less in propofol, Seizure time was shorter with propofol as well as side effects were less with propofol. Conclusion: Propofol as compared to thiopentone sodium had smooth rapid induction with hemodynamic stability with reduced duration of seizure activity without affecting efficacy ECT and faster recovery with minimal side effects during recovery. Thus propofol can be used as a safe anaesthetic as induction agent for ECT.

Key Words: - Tonus, clonus, hemodynamic parameters, seizure duration.
\end{abstract}

*Address for Correspondence:

Dr Kiran B Sonawane, Assistant Professor, Department of Anesthesia, Government Medical College and Hospital, Jalgaon. 425001. India.

Email: drkiran6669@gmail.com

Received Date: 28/03/2020 Revised Date: 07/05/2020 Accepted Date: 14/06/2020

DOI: https://doi.org/10.26611/10151521

This work is licensed under a Creative Commons Attribution-NonCommercial 4.0 International License.

$(\mathrm{cc})$ BY-NO

\begin{tabular}{|l|l|}
\hline \multicolumn{2}{|c|}{ Access this article online } \\
\hline Quick Response Code: & Website: \\
\hline & www.medpulse.in \\
\cline { 2 - 2 } & \\
\hline
\end{tabular}

\section{INTRODUCTION}

Convulsive therapy is used to control grand mal seizures usually at a number of days to achieve a change in abnormal mental state of psychotic patients. Electroconvulsive therapy was introduced about a half century ago as treatment for schizophrenia and depression, and was used exclusively for this disorder for many years. The generalized epileptic seizure was produced using electroconvulsive therapy ECT without anaesthesia in
1938 for almost 30 years $^{1}$. Effect of ECT is less when initial seizure duration is either very short or very long ${ }^{2}$. The therapeutic effect depends upon the production of the generalized convulsion and there may be a minimum duration of seizure necessary for successful treatment. It is important to study the effect of the anaesthetic technique on ECT - induced seizures, because the response to ECT may be attenuated if anaesthesia abolishes or inhibits seizure. To provide effective anesthesia to patients who may benefit from ECT, the anesthesiologist must be equipped with an in-dept knowledge and technical skill in this segment of anaesthetic practice. The duration of anaesthesia for each ECT treatment session is short. Patients presenting for ECT are frequently receiving multiple drug therapy and have a high incidence of other medical conditions and advancing age. Many patients having ECT are returned to psychiatric units with low numbers of medically trained nurses after the procedure and often discharged home into the care of non-medically trained relatives. For these reasons, the desirable characteristics of anaesthetic agents used for ECT should 
provide a smooth, rapid induction, a rapid recovery, alteration of physiological effects of ECT as well as minimal antagonistic effects on seizure activity. Further they must be compatible with a wide range of drugs and not interfere with the efficacy of ECT. Propofol is associated with less gastrointestinal side effects and better recovery from side effects after the ECT procedure and better cognitive recovery also ${ }^{3}$. We have compared thiopentone, which is the usual anaesthetic agent used in our hospital for ECT, with propofol. We examined particularly the induction and recovery characteristics; quality of seizure as well as side effects of both drugs. The study was repeated measure crossover design in which each patient served his or her own control. This design minimizes the variation in the ability to cooperate by the psychiatric patients, the effect of different medications on the recovery from anaesthesia and physiological variations in response to ECT. This study aimed for comparison between thiopentone sodium and propofol as inducing agents for electroconvulsive therapy. Primary objectives were to study the haemodynamic changes during ECT with use of thiopentone sodium and propofol. Secondary objectives were to study the seizure response and duration while using the two induction agents, study the patient recovery after ECT, to study the side effects of both agents at induction and recovery.

\section{MATERIALS AND METHODS}

This study was conducted at BJMC and Sasoon hospital, Pune. Ethical committee approval was taken prior to the start of study. 60 patients were recruited of ASA grade I or II with no absolute contraindication to ECT. Informed consent was obtained from each patient or from appropriate relative. Complete history and physical examination was done before starting treatment. In case record form body weight was recorded along with routine investigations like $\mathrm{Hb}, \mathrm{CBC}$, fasting blood glucose, blood urea, serum creatine, LFT, ECG and X ray chest were done before taking up for ECT. Current medications were recorded and kept constant throughout the study. The ECT was carried out in morning with the patients fasting overnight. Patients requiring additional sedation on the day of treatment were excluded from the study. Intravenous atropine $0.6 \mathrm{mg}$ was given just before induction got anaesthesia. All patients were given around 6 to 8 ECT treatments on Monday, Wednesday and Saturdays of each week. The patients were randomly allocated so that the half were anaesthetized with $2.5 \%$ thiopentone sodium (Group I) and the other half with $1 \%$ propofol (Group II). The thiopentone $5 \mathrm{mg} / \mathrm{kg}$ and propofol $1.5 \mathrm{mg} / \mathrm{kg}$ were given over 20 seconds through an indwelling needle in a vein on the dorsal of the hand. The induction dose was considered adequate if the eyelash reflex was lost after 30 seconds, otherwise additional agent was titrated as necessary. The sleep dose was recorded for subsequent treatment. Suxamethonium $0.6 \mathrm{mg} / \mathrm{kg}$ was given when the patient was asleep. A mouth prop was inserted and a bitemporal ECT was performed. Current at 90 to 110 mili volts for $0.5 \mathrm{secs}$ in sine wave instrument 0.1 secs in brief pulse. 110 volts given for 0.5 seconds. The settings and position of electrodes were kept constant by the psychiatrist. The mouth prop was changed to guedel airway after the seizure and ventilation assisted with the face-mask with $100 \%$ oxygen at the rate of one breath every 5 seconds until return of spontaneous respiration. Monitoring - Pulse and BP were monitored at baseline after atropine, after induction and after scoline, then $0 \mathrm{~min}$ and every $1 \mathrm{~min}$ after completion of seizure until the 15 mins. Seizure response to ECT was graded as follows: tonus :-good facial muscle contraction only, moderate - facial muscle, shoulders and other parts and poor - severe contraction of all muscles. Clonus:- good-movement of facial muscles and platysma, with slight movement at joints between the long bones, moderate-the above plus slight muscle movement and poor - severe movement of all muscles. Specific side effects during induction and recovery were recorded. The time from induction until ECT, the time from ECT to the end of the seizure (seizure time) and the duration of apnea were recorded. During recovery, the time to opening the eyes on command and being able to walk unaided were noted. For the comparisons, $P<0.05$ was considered to be statistically significant. The power of the study being adequate, data were analyzed using the software package SPSS version 23 by using t-test, Z test, Mann Whitney U test, and Wilcoxon test.

\section{RESULTS AND OBSERVATIONS}

Mean age of group 1 (Thiopentone sodium) was 36.7 and group 2 (Propofol) was 32.6 with 15 males $n 15$ females in each group. Mean weight of patients was less in group 2 (54.3) as compared to group in 1(57.5) before start of the study. Patients suffering from different psychiatric illness were taken for the study including schizophrenia, chronic schizophrenia, schizophrenia with mental retardation, paranoid depression, alcohol induced psychosis, acute psychotic illness, mania. Baseline systolic blood pressure and diastolic blood pressure and pulse rate per minute. (Table 1 and figure 1) shows systolic blood pressure was not significantly decreased in both group but diastolic blood pressure was less with propofol. Pulse rate was less after induction with propofol. 
Table 1: Baseline SBP, DBP Pulse rate / min

\begin{tabular}{ccccc}
\hline & $\begin{array}{c}\text { Group 1 } \\
\text { (Thiopentone Sodium) }\end{array}$ & $\begin{array}{c}\text { Group 2 } \\
\text { (Propofol) }\end{array}$ & t test & p value \\
\hline SBP mm Hg & $118.1(23.7)$ & $119(16.9)$ & 0.176 & 0.861 \\
DBP mm Hg & $83.1(9.0)$ & $79.7(7.6)$ & 1.617 & 0.111 \\
Pulse rate/min & $105.3(19.2)$ & $109.8(24.2)$ & 0.792 & 0.43 \\
\hline
\end{tabular}

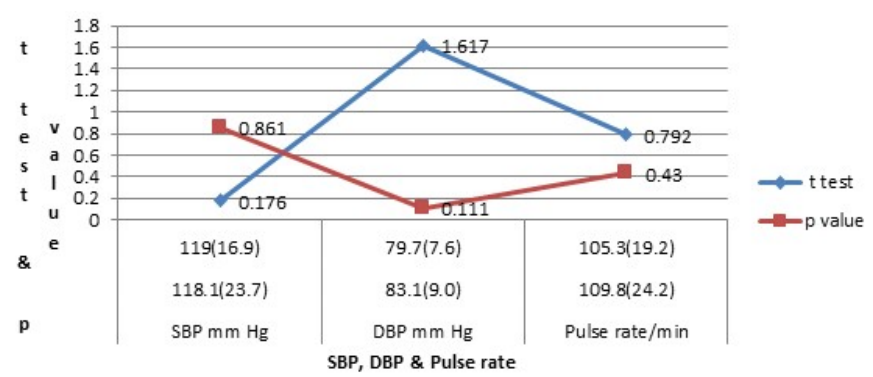

Figure 1: showing Baseline SBP, DBP Pulse rate / min

Table 2 and figure 2 depicts the seizure response and duration of seizure in seconds in ECT after giving anaesthesia. Seizure response and duration of seizure was short with propofol as compared to thiopentone sodium.

Table 2: Seizure response and duration of seizure (seconds)

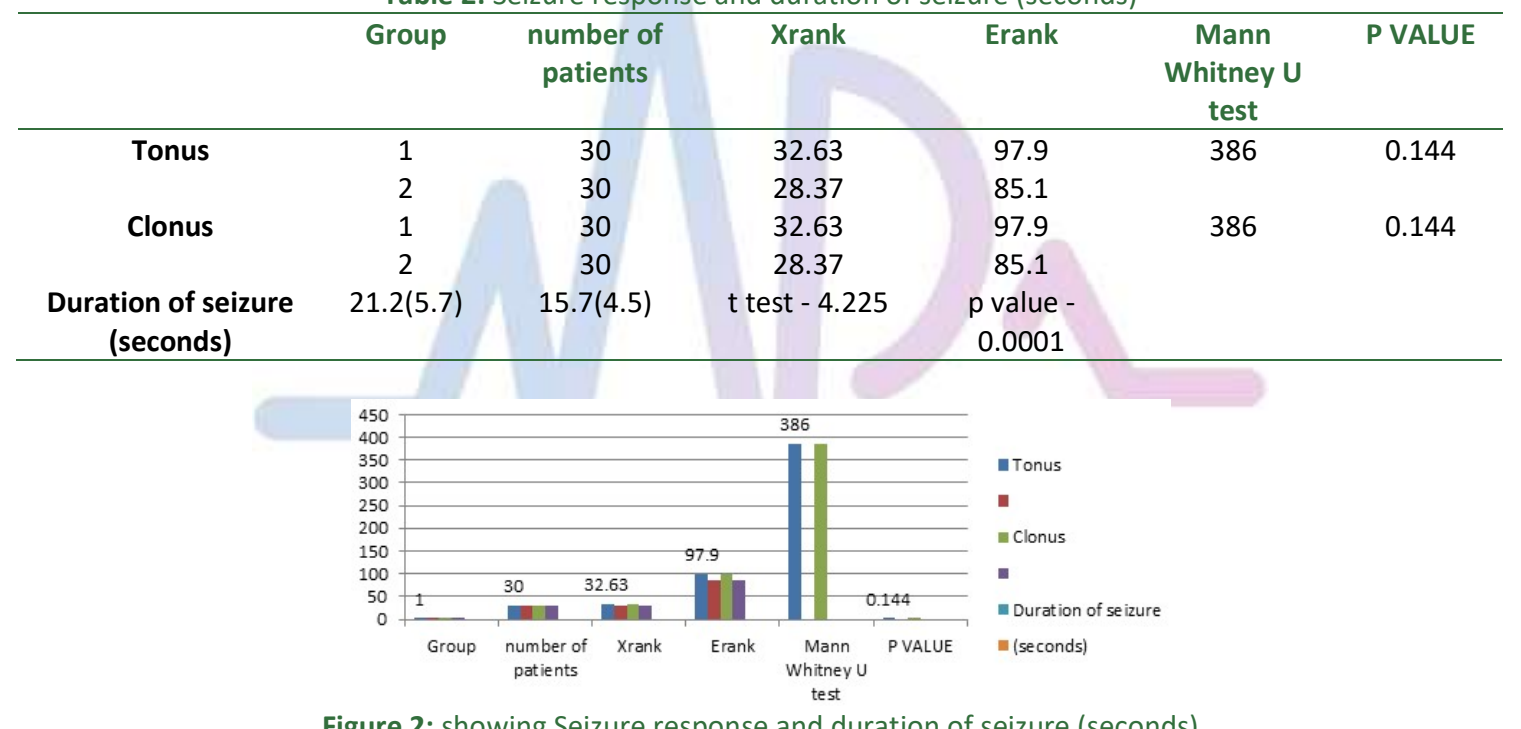

Figure 2: showing Seizure response and duration of seizure (seconds)

Table 3 and figure 3 depicts side effects on induction shows cough, laryngospasm were less with propofol as compared to thiopentone sodium while discomfort on injection is more with propofol.

Table 3: Side effects on induction

\begin{tabular}{ccc}
\hline Side Effect & Group 1 & Group 2 \\
\hline Absent & 23 & 24 \\
Discomforts on injection & 2 & 5 \\
Cough & 4 & 1 \\
Laryngospasm & 1 & 0 \\
\hline Total & 30 & 30 \\
\hline
\end{tabular}




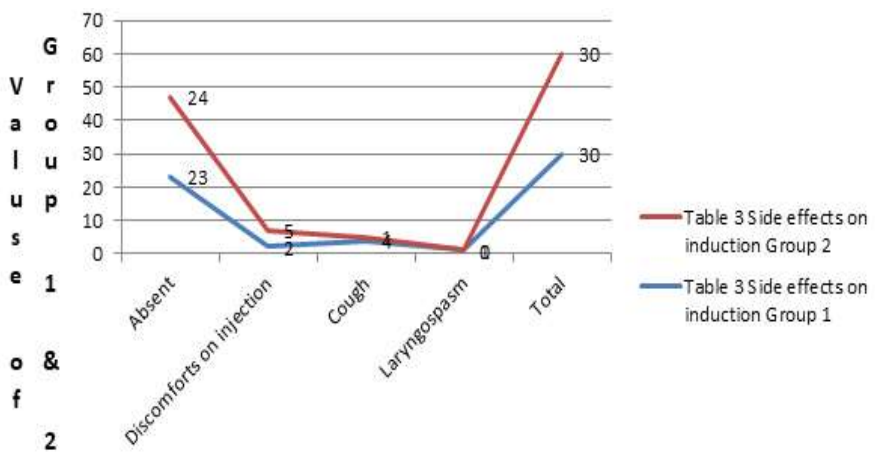

Side effects

Figure 3: Side effects of induction on group 1 and group 2

Table 4 and figure 4 shows side effects on recovery like confusion, headache, diplopia, redness of eye and flush was more with thiopentone sodium except euphoria as compare to propofol.

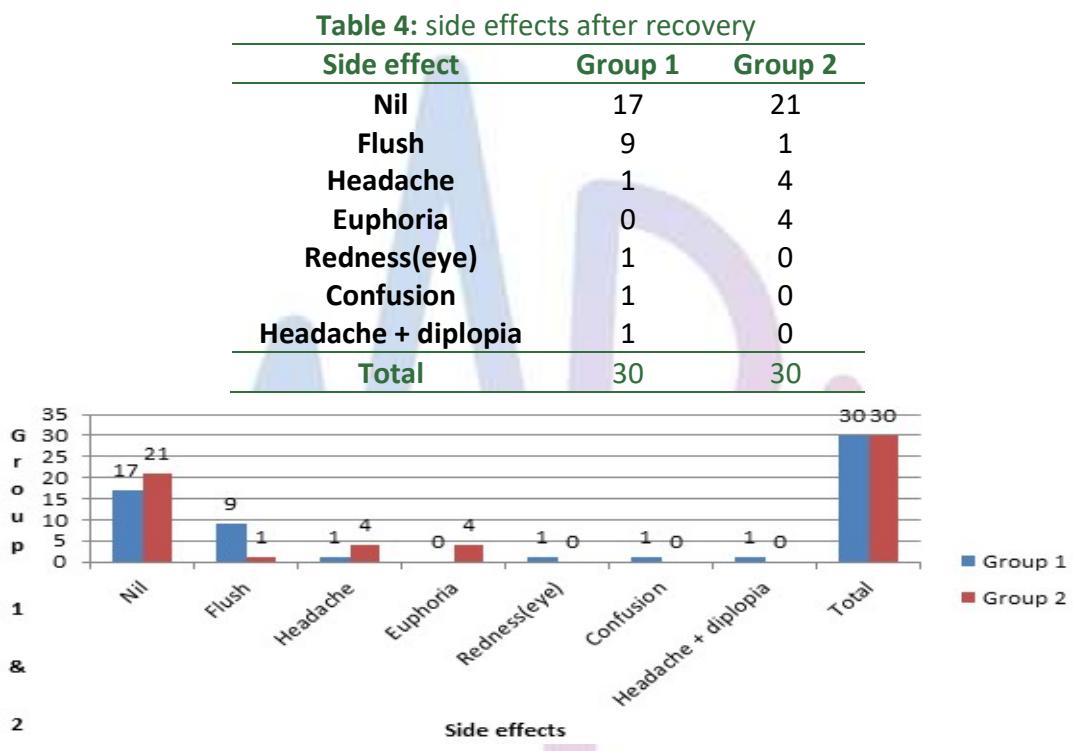

Figure 4: side effects after recovery

\section{DISCUSSION}

Electro convulsive therapy still retains a place in modern psychiatric practice. Ideal anaesthesia should be rapid in induction with rapid recovery with relief of physiological effects of ECT. We have compared thiopentone sodium(Group 1) and propofol (Group 2) as inducing agents for ECT. Baseline values of pulse rate, systolic and diastolic BP were recorded and compared in 2 groups and found not to be significant. Even after giving atropine $0.6 \mathrm{mg}$ BP and pulse rate were recorded and was not significant except for diastolic BP which showed significant difference. This was seen in accordance with Boey and Lai et al. ${ }^{4}$. also with Bone et al. ${ }^{5}$ showed decrease in diastolic bp after induction with propofol. In our study after completion of seizure, systolic bp was increased in Thiopentone group as compared to propofol group which was seen in accordance with Bone et al. ${ }^{5}$ and
Lim et al. ${ }^{6}$. Pulse rate at induction was insignificant in our study, but after completion of seizure the pulse rate increased in both the groups but rise in group 1 was significantly higher as compared to group 2 which was seen in accordance with Rampton et al. ${ }^{7}$ where heart rate following propofol was significantly lower than methohexital at all times after induction. This lower pulse rate with propofol attributed to resetting of baroreflexes to allow slower heart rates at lower arterial pressure. The reduction in heart rate may be favorable effect on myocardial oxygen demand. The seizure response and mean duration was studied in both groups and in group 2 it was significantly decreased. Seizure time was shorter with propofol as compared to thiopentone sodium which was seen in accordance with Rouse et al. ${ }^{8}$ and Martin et al. ${ }^{9}$. In Martenson et al. ${ }^{10}$ study, there was reduced seizure duration with propofol in comparison with methohexitone 
and thiopentone sodium. Tonus clonus responses were similar in our study whereas in Boey and Lai et al. ${ }^{4}$ study showed better tonus and clonus with propofol. In our study faster recovery was seen with propofol also induction to walking time was significantly different with propofol suggesting faster recovery. Side effects in propofol group were less as compared to that of thiopentone group.

\section{CONCLUSION}

On conclusion propofol as compared to thiopentone sodium had smooth rapid induction with hemodynamic stability with reduced duration of seizure activity without affecting efficacy ECT and faster recovery with minimal side effects during recovery. Thus propofol can be used as a safe anaesthetic as induction agent for ECT.

\section{ACKNOWLEDGMENTS}

I acknowledge Dr Sandipbhai Patel Associate Professor and Head of Department for continuous guidance and motivating for research article. Also thanks to my family for constant support.

\section{REFERENCES}

1. Ding Z, White PF. Anesthesia for electroconvulsive therapy. Anesth Analg 2002;94:1351- 64.

2. Villalonga A, Bernardo M, Gomar C, Fita G, Escobar R, Pacheco M. Cardiovascular response and anesthetic recovery in electroconvulsive therapy with propofol or thiopental. Convuls Ther 1993;9:108-11.

3. Butterfield NN, Graf P, Macleod BA, Ries CR, Zis AP. Propofol reduces cognitive impairment after electroconvulsive therapy. J ECT 2004;20:3-9

4. Boey WK, Lai FO. Comparison of propofol and thiopentone as anaesthetic agents for electroconvulsive therapy. Anaesthesia. 1990 Aug;45(8):623-8.

5. Bone ME, Wilkins CJ, Lew JK. A comparison of propofol and methohexitone as anaesthetic agents for electroconvulsive therapy. European journal of anaesthesiology. 1988 Jul;5(4):279-86.

6. (Lim SK, Lim WL, Elegbe EO. Comparison of propofol and methohexitone as an induction agent in anaesthesia for electroconvulsive therapy. West African journal of medicine. 1996;15(4):186-9.)

7. Rampton AJ, Griffin RM, Stuart CS, Durcan JJ, Huddy NC, Abbott MA. Comparison of methohexital and propofol for electroconvulsive therapy: effects on hemodynamic responses and seizure duration. Anesthesiology. 1989 Mar;70(3):412-7.)

8. Rouse EC. Propofol for electroconvulsive therapy: a comparison with methohexitone. Preliminary report. Anaesthesia. 1988 Mar;43:61-4.

9. Martin BA, Cooper RM, Parikh SV. Propofol anesthesia, seizure duration, and ECT: a case report and literature review. The journal of ECT. 1998 Jun;14(2):99-108.

10. Mårtensson $\mathrm{B}$, Bartfai $\mathrm{A}$, Hallén $\mathrm{B}$, Hellström $\mathrm{C}$, Junthé $\mathrm{T}$, Olander M. A comparison of propofol and methohexital as anesthetic agents for ECT: effects on seizure duration, therapeutic outcome, and memory. Biological psychiatry. 1994 Feb 1;35(3):179-89.

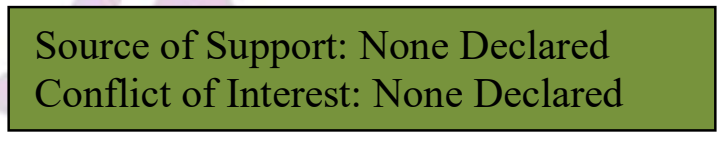

Policy for Articles with Open Access:

Authors who publish with MedPulse International Journal of Anesthesiology (Print ISSN:2579-0900) (Online ISSN: 2636-4654) agree to the following terms: Authors retain copyright and grant the journal right of first publication with the work simultaneously licensed under a Creative Commons Attribution License that allows others to share the work with an acknowledgement of the work's authorship and initial publication in this journal.

Authors are permitted and encouraged to post links to their work online (e.g., in institutional repositories or on their website) prior to and during the submission process, as it can lead to productive exchanges, as well as earlier and greater citation of published work. 